afforded to him by the bath. In ten minutes, he was joking with his friends, and enjoying himself thoroughly. The water in the bath was so continuously heated by the body of the patient, that it was with difficulty lowered to $70 \mathrm{deg}$. and to $60 \mathrm{deg}$. by constant baling out. With the recovery of the patient's consciousness, the use of the thermometer in the mouth became possible, and it was found that the upward movement of the temperature had been arrested. In this bath, cold affusions being poured continuously over the head and shoulders, the patient remained for forty-five minutes, when the thermometer had fallen slowly to IOI. 5 leg. He was still very comfortable and had no chill. He was now removed to bed, placed in a warm dry blanket, and a bottle put to his feet. His aspect and manner had for some time been perfectly natural, and his pulse and respirations were scarcely excessive. During the few hours which followed the bath, the temperature slowly fell to the normal. From this time forward, recovery was steady, and may have been aided by a few liberal doses of quinine, given with a view of preventing any renewal of the fever. It is but fair to add that the efforts of the medical men were admirably seconded by a nurse from the Bradford Institution, upon whom much necessarily devolved, and who carefully watched and recorded the temperatures throughout.

\section{A NOTE ON ANTISEPTICISM AND COTTON-WOOL.}

By SA M S O N G M GE E, F.R.S.Ed.,

Surgcon to the Queen's Hospital, Birmingham; President of the Birmingham and Midland Counties Branch of the British Medical Association; etc.

TuE interest which must attach to any surgical communication from Dr. Marion Sims is, in the present state of surgical opinion, possessed in an exceptional degree by his letter on antiseptic surgery, published in the number of this periodical for October 27th. Dr. Sims states that "in France antisepticism can hardly be said to have a foothold"; but, with all deference to my distinguished American friend, the theory and practice had its earliest advocates across the Channel. Without engaging in the question of priority between Lemaire and Déclat, it is on record that the latter, in 1861, applied carbolic oil (one part in ten) to gangrenous sores; that after that, Maisonneuve extensively used carbolic lotions in the Hôtel Dieu; and that in October 1865, Déclat advocated carbolism on the basis of Pasteur's germ-theory. Those who have not had an opportunity of reading his work* may be interested by a literal translation of two short passages.

"The fine researches of $M$. Pasteur give the explanation of these unexpected phenomena - the prevention of purulent infection, hospital gangrene, etc., by alcohol, camphor, and carbolic acid. Wherever there is decomposition (alteration) of an organic liquid or substance, it is caused by the physiological action of living beings, of which the germs pullulate in the air."

"It is to-day well demonstrated that carbolic acid and its compounds prevent the development and even partly destroy the germs in the air ; accordingly, it is easy to understand the favourable action of that acid in all kinds of wounds, in burns, and in midwifery."

Dr. Marion Sims's testimony to the value of cotton-wool dressing is important additional testimony to that already at hand in its favour. Burggraeve of Ghent distinguished himself as an early and zealous advocate of the appareil ouaté. Still earlier (1842), Mathias Mayor, t taking for his motto Simplex sigillum veri, demonstrated and recorded the uses of cotton-wool as a dressing for wounds, with the originality and the ingenuity which characterised him as a facile prin. ceps of surgical art.

What an interesting chapter might be written on surgical fashions ! How true is it, to quote Charles Bell, that if we are not acquainted with the history of the art, and not aware of the observations and discoveries of the great men who have preceded us, we are in constant danger, in straining after new inventions, of only restoring what has been discovered, tried, and rejected before our time. In the treatment of wounds, two causes above all others have tended to retard progress - firstly, imperfect acquaintance with principles and methods which, in spite of their soundness, have remained comparatively unknown ; secondly, the attractiveness of theoretical generalisations, which fascinate the majority and not unfrequently obscure the judgment of the most conscientious advocates. To take for granted that putrefaction and suppuration are identical, and to attempt a reform of surgical practice by the light of Pasteur's germ-theory, is an enterprise which calls for the strictest investigation. What is wanted is an ex-

* Nouvelles Applications de $r$ Acide Phénique en Médecine et en Chirurgie, par le

Dr. G. Déclat. Paris, Delahaye Ed., Octobre 1865, pp. 27-29.
† La Chirurgie simplifiée. Bruxelles, x842. haustive empirical inquiry into the various methods of treating wounds, with the full knowledge of acquired facts, and without theoretical preoccupation. The old teaching of Alanson and Mynors, of John Bell and Larrey, of Mayor and Seutin, is substantially as sound now as it was in their day. To investigation and treatment, the thermometer and a variety of chemical and mechanical appliances will be found invaluable aids; but the judiciously progressive surgeon has no need of a revolution. If he make discriminative use of facts known to his predecessors and contemporaries, he will only need a well stored surgical head and gentle hands to make him a very successful healer of wounds, without the constant dread of M. Pasteur's reputedly ubiquitous and maleficent germs.

\section{PERFECT RESTORATION OF THE SHAFT OF THE ULNA AFTER ITS COMPLETE NECROSIS AND EXFOLIATION.*}

\section{By A. W. STOCKS, M.R.C.S.Eng., Salford.}

IN the first week in $1876, \mathrm{H}$. J., aged 16 , having received no injury, had an aching pain in his right wrist. Next day, he was unable to work as a "drawer-in" in the mill, an occupation which requires a fair amount of manual dexterity. His arm began to swell on the ulnar side gradually from the wrist up to the elbow. An abscess formed and burst naturally at the lower end of the ulna, at the termination of the first fortnight of the disease. He came under my care on March 18th, when I found an opening in the arm, which was much swollen, near the styloid process of the right ulna, through which bare bone could be felt as far towards the elbow as the probe would reach. There was an abscess behind the head of the ulna, and the parts about the elbow were much thickened.

On March 23rd, after the application of Esmarch's bandage and of chloroform, the opening was enlarged freely towards the elbow, and the piece of bone produced, measuring six inches and a half in length, and involving the whole thickness of the bone, was removed. The longitudinal measurement of the left ulna was nine inches. Small osseous deposits could be felt in the periosteum on the finger being introduced into the cavity, the periosteum itself having apparently sustained very little injury. The wound was filled with lint saturated with carbolised oil, and a bandage applied over the whole arm, with a view of controlling the hremorrhage when the blood was allowed to return into it. The arm was placed on an angle splint in the prone position. Next day, the lint and bandage were removed, and there was very slight hæemorrhage.

March 28th. The wound was granulating. He could bend the elbow slightly.

April 14th. The arm was put in a straight splint, with the hand free. Formation of bone could be distinctly recognised. II could pick up any light object fron the floor.

June $13^{\text {th. }}$ He could write his name.

June $23 \mathrm{rd}$. There was slight power of pronation and supination. Small pieces of sequestrum came away from the inner side of the head of the ulna, the wound finally healing in the month of August last. The bone, being chiefly subcutaneous, can now be felt to be perfectly continuous and very nearly of its original shape.

It would seem that this case was one of idiopathic inflammation of the bone, both endosteum and periosteum being involved, followed by necrosis of the whole shaft of the bone. The chief interest in this case appears to be in the fact of the perfect restoration of the limb after such severe injury, and in showing the wonderful power of repair possessed by the human body when placed under favourable circum. stances.

\section{OBSTETRIC MEMORANDA.}

\section{PUERPERAL EMPHYSEMA.}

BEING a reader of the JouRNAL for some time, and finding there the only cases of puerperal emphysema I can discover on record, I think I should report a case which came under my observation.

Last March, I was called to see a woman, aged 20 , in her first labour. On my arrival, I found the os half dilated, and, about ten minutes afterwards, the waters escaped and the head came down slowly for about an hour and a half; then the pains became very violent, and, on examination, I found the head impacted between the ischial tuber-

* Read in the Section of Surgery at the Annual Meeting of the British Medical Association in Manchester, August 1877 . 